\title{
Dendroctonus micans (Kugelann) (Coleoptera: Curculionidae, Scolytinae)'ın konukçu seçimini etkileyen bazı özellikler: Artvin ladin ormanlarından deneysel sonuçlar
}

\section{Some tree features affecting host selection by Dendroctonus micans (Kugelann) (Coleoptera: Curculionidae, Scolytinae): Experimental results from Artvin spruce forests}

\author{
Hazan ALKAN AKINCI ${ }^{1}$, Funda ERŞEN BAK ${ }^{1}$, Bahtiyar Ali ÇALIŞKAN ${ }^{2}$ \\ ${ }^{1}$ Artvin Çoruh Üniversitesi Orman Fakültesi Orman Mühendisliği Bölümü Artvin, Türkiye \\ ${ }^{2}$ Artvin Çoruh Üniversitesi Fen Bilimleri Enstitüsü Artvin, Türkiye
}

\section{Eser Bilgisi / Article Info}

Araştırma makalesi / Research article DOI: $10.17474 /$ artvinofd.446259

Sorumlu yazar / Corresponding author Hazan ALKAN AKINCI

e-mail: hazan.akinci@artvin.edu.tr ORCID: 0000-0002-5618-289X

Geliş tarihi / Received

20.07.2018

Düzeltme tarihi / Received in revised form

13.11.2018

Elektronik erişim / Online available

19.11.2018

Anahtar kelimeler:

Dendroctonus micans

Doğu ladini

Konukçu seçimi

Konukçu ağaç özellikleri

Keywords:

Dendroctonus micans

Oriental spruce

Host selection

Host tree features

\begin{abstract}
Özet
Kabukböcekleri orman böcekleri içerisinde kurumalara ve ağaç ölümlerine yol açan en önemli zararlılardandır. Kuzey yarı kürede Dendroctonus ve Ips türleri periyodik olarak büyük populasyonlar oluşturarak, birkaç yıl içerisinde geniş meşcerelerde milyonlarca sağlıklı ağacın ölümüne yol açmıştır. Ülkemizde 1966 yılında tespit edilen Dendroctonus micans (Kugelann) (Coleoptera: Curculionidae, Scolytinae) salgın populasyonları oluşturarak milyonlarca metreküp ladin ağacının kurumasına neden olmuştur. Günümüzde Artvin ve Giresun ladin ormanlarının tamamına yayılmış olan $D$. micans, Trabzon ladin ormanlarındaki yayılışını sürdürmektedir ve yayılış hattının ön cephesinde ağaç kurumalarına neden olmaktadır. $D$. micans yaralı ve devrik ağaçlara saldırması yanında, görünüşte sağlıklı olan ağaçlara da saldırmaktadır. Böceğin başarılı bir şekilde yerleştiği ve başarısız olduğu saldırı girişimlerinin nedenleri $D$. micans'ın konukçu seçimi hakkındaki soruların odak noktasını oluşturmaktadır. Bu çalışmada, D. micans'ın konukçusuna yerleşmede başarısını etkileyen bazı etmenler deneysel olarak araştırılmıştır. Artvin Orman İşletme Müdürlüğü, Taşlıca Orman İşletme Şefliği ladin ormanlarında, meşcere kapalılığı içerisinde bulunan, 1975 m ve 1680 m yükseltideki iki farklı saf ladin meşceresinde çalışıımıştır. Daha önce $D$. micans saldırısı bulunmayan ladin ağaçlarına böceğin dişi erginleri yerleştirilmiştir. İlk deneme alanında 37, ikinci deneme alanında 36 ladin ağacında çalışılmıştır. Arazi çalışmaları 1 Haziran - 5 Kasım 2015 tarihleri arasında yürütülmüştür. Deneyin sonunda, böceğin başarılı bir şekilde yerleştiği ve başarısız olduğu ağaçların periyodik büyümeleri, bazı hasılat verileri, floem kalınlıkları, floemin nem miktarı, floemdeki karbon ve azot miktarı istatistik analizlerle karşılaştırılmıştır. Sonuç olarak, D. micans'ın son 10 yıldır artımın azaldığı, tepe boyunun kısa olduğu ve floemin azot içeriğinin fazla olduğu ladin ağaçlarına başarılı bir şekilde yerleştiği tespit edilmiştir. Bu çalışmanın sonuçları, D. micans'ın konukçu seçimi ile ilgili temel bilgilerin ortaya koyulmasına katkı sağlamıştır. Böceğin başarılı bir şekilde yerleşebileceği ağaçların tahmin edilebilmesi, uygulayıcılara mücadele çalışmalarında kolaylık sağlayacaktır.
\end{abstract}

\begin{abstract}
Bark beetles are one of the most important group in forest pests that attack trees and cause tree deaths. Bark beetles such as Dendroctonus and Ips species have built up large populations periodically and have killed millions of trees in several years in northern hemisphere. Dendroctonus micans (Kugelann) (Coleoptera: Curculionidae, Scolytinae) that has been first discovered in 1966 in Turkey has built up outbreak populations and has killed millions of spruce trees. D. micans is present in all the spruce forests in Artvin and Giresun, and it has an expanding front in Trabzon. It has endemic population in Artvin and Giresun, but it causes tree deaths in Trabzon. D. micans attacks apparently healthy trees besides wounded trees and windthrowns. Causes of the successful and aborted attacks are the focal point of the questions about host selection by $D$. micans. In this study, causes that affect $D$. micans successful establishment to its host have been experimentally investigated. Field works have been performed at Artvin Forestry Enterprises Taşlıca Forest District, at two different pure spruce stands that were in stand closure at $1975 \mathrm{~m}$ and $1680 \mathrm{~m}$ a.s.l. D. micans females have been inserted to unattacked spruce trees. This experiment has been arranged on 37 and 36 trees in the first and second study plot, respectively. Field works have been performed through 1 June -5 November 2015. At the end of the experiment, periodic growth, some yield parameters, phloem thickness, phloem moisture and amount of $\mathrm{C}, \mathrm{N}$ in phloem have been compared statistically. As a result, it has been found that $D$. micans successfully establishes on the trees that has decreasing growth in the last 10 years, shorter crown length and higher $\mathrm{N}$ in the phloem. Results of this study contribute to the subject of host selection by $D$. micans. Estimating the trees that the beetle can establish successfully will ease the work of practitioners during control studies.
\end{abstract}




\section{Giriş}

Dendroctonus micans 19. yüzyılın ilk yarısından itibaren Almanya, Belçika, Danimarka, Hollanda ve Fransa'da salgınlar meydana getirerek, ciddi zararlara ve ağaç ölümlerine neden olmuştur (Severin 1902). D. micans, günümüzde Avrupa ve Asya'da ladinin yetiştiği alanların tamamında bulunmaktadır. Çeşitli iklim ve orman şartlarına uyum sağlayabilmektedir. Fransa, Gürcistan, Türkiye ve İngiltere'de yakın tarihlerde ulaştığı bölgelerdeki şiddetli zararını sürdürmektedir (Khobakhidze 1967; Acatay 1968; Carle et al. 1979; Alkan 1985; Grégoire 1988; Fielding et al. 1991; Fielding ve Evans 1997).

Avrupa'daki salgınların yanında, doğu ladini Picea orientalis (L.) Link. ormanlarında ilk defa 1957 yılında Gürcistan'da tespit edilmiştir. Tespit edilmesinden altı yıl sonra, böceğin, 1963'te 100.000 ha'dan fazla doğu ladini meşceresini istila ettiği ve ağaç ölümlerine neden olduğu kaydedilmiştir (Khobakhidze 1967). Türkiye'de ilk defa 1966 yılında Erzurum Orman Bölge Müdürlüğü Ardahan İşletmesi Posof ormanlarında tespit edilmiştir (Acatay 1968). 1970'li yılların başından itibaren sırasıyla Artvin, Giresun ve Trabzon ladin ormanlarına yayılmıştır. Bu ormanlarda büyük salgın populasyonları oluşturarak milyonlarca metreküp ağacın kurumasına neden olmuştur (Serez 1979; Alkan 1985; Eroğlu 1995; Alkan-Akıncı et al. 2009). Günümüzde Artvin ve Giresun ladin ormanlarının tamamına yayılmış olan D. micans, Trabzon ladin ormanlarındaki yayılışını sürdürmektedir ve yayılış hattının ön cephesinde ağaç kurumalarına neden olmaktadır (Alkan-Akıncı et al. 2014).

Avrupa'daki salgınların ilk kaydedildiği günden (Severin 1902) buyana araştırmacılar böceğin saldırılarının tüm yönlerini içeren çalışmalar yapmışlardır. Farklı ülkelerdeki genel durumun, böceğin yayılışının özelliklerinin, saldırı stratejisinin, biyolojisinin, gelişiminin, kimyasal ekolojisinin, konukçu tercihinin, konukçu dayanıklılığının, böcekle mücadele stratejilerinin irdelendiği çalışmalar yapılmıştır (Carle 1975; Grégoire 1985, 1988; Storer et al. 1997; Gilbert et al. 2001, 2003; Lieutier 2007 - sadece seçilmiş bazı çalışmalara atıf yapılmıştır). Türkiye'de, bugüne kadar, böceğin zarar durumunun bazı yönleri, biyolojisi, saldırı stratejisi ve mücadele yöntemlerini içeren araştırmalar yapılmıştır (Besçeli et al. 1968; Serez 1979; Alkan 1985; Alkan ve Aksu 1990; Eroğlu 1995; Selmi 1998; Aksu 2011; Göktürk et al. 2011; Alkan-Akıncı et al. 2009, 2014, - sadece seçilmiş bazı çalışmalara atıf yapılmıştır).

Alkan-Akıncı et al. (2014), D. micans'ın Türkiye'de doğu ladinindeki saldırı stratejisi ve gelişimini böceğin doğal saldırısı altındaki doğu ladini ormanlarında araştırmıştır. Bu çalışmanın sonuçlarına göre, ladin ağaçlarının \%21,7'si böceğin zararına uğramıştır. Saldırıya uğrayan ağaçların çoğunda sadece bir tane başarılı giriş deliği bulunmuştur. Saldırı yoğunluğu saldırıya uğrayan ağaçların birçoğunda sınırlı kalırken, belli ağaçlarda oldukça yüksek olmuştur (tek bir ağaçta 40 ile 160 saldırı girişimi). D. micans çoğunlukla yaralı ağaçlara saldırmış ve bu ağaçlara başarılı şekilde yerleşmiştir.

Bu sonuçlara göre, D. micans'ın yaralı ağaçların bulunduğu bir meşcerede öncelikle / çoğunlukla bu ağaçlara saldıracağını tahmin etmek mümkündür. Bu çalışmanın sonuçları arasında dikkat çeken bir diğer sonuç ise belli ağaçlar üzerinde saldırı yoğunluğunun çok yüksek olmasıdır. Saldırıya uğrayan ağaçların çoğunda sadece bir tane başarılı giriş deliği kaydedilmesine rağmen bazı ağaçlarda 40 ile 160 saldırı girişimi tespit edilmiştir. Çokça saldırıya maruz kalan bu belli sayıdaki ağaçların özelliklerinin ortaya konulmasına ihtiyaç vardır. Bu ağaçlar bir meşcerede $D$. micans populasyonun katlı bir şekilde artmasını sağlayan, salgının başlamasına öncülük eden ağaçlar olabilmektedir.

Canlı konukçuların kabukböceklerine karşı duyarlılıkları tüm ağacı etkileyen faktörlere dayalı olarak ortaya konulmuştur. D. ponderosae Pinus contorta üzerindeki mekanik yaraların çevresinde karbonhidrat içeriğinin fazla olduğu yerleri tercih etmiştir. D. frontalis'in ilk dönem larvalarının floemin nem içeriğinin düşük olduğu kabukta daha yavaş geliştiği kaydedilmiştir (Storer ve Speight 1996). Storer ve Speight (1996), D. micans'ın, mekanik bir yara çevresinde floemin nem içeriğinin fazla olduğu alanlara daha büyük olasılıkla yumurta koyacağını belirtmiştir. Aynı zamanda floemin nem içeriğinin azot miktarıyla pozitif yönde ilişkili olduğunu göstermiştir. 
Bu çalışmada, D. micans'ın bir konukçuya yerleşirken başarısını etkileyen bazı etmenler deneysel olarak araştırılmıştır. Bu amaçla, arazi koşullarında biyolojik deney düzenlenmiş ve böceğin başarılı bir şekilde galeri oluşturduğu ve başarısız olduğu ağaçların periyodik büyümeleri, bazı hasılat verileri, floem kalınlıkları, floemde taşınan organik madde miktarı istatistik analizlerle karşılaştırılmıştır. Elde edilen sonuçlar, böceğin doğu ladini ormanlarındaki ekolojisi ve konukçu seçimi konusundaki literatüre katkı sağlayacaktır. Ayrıca, böceğin başarılı bir şekilde yerleşebileceği ağaçların tahmin edilebilmesi uygulayıcılara mücadele çalışmalarının başarısını ve etkinliğini arttıracak bilgi sunacaktır.

\section{MATERYAL VE YÖNTEM}

Arazi çalışmaları Artvin Orman İşletme Müdürlüğü, Taşlıca Orman İşletme Şefliği ladin ormanlarında gerçekleştirilmiştir. Meşcere kapalılığı içerisinde bulunan, $1975 \mathrm{~m}$ ve $1680 \mathrm{~m}$ yükseltideki iki farklı saf ladin meşceresinde çalışılmıştır. Arazi çalışmaları 1 Haziran - 5 Kasım 2015 tarihleri arasında yürütülmüştür.

\section{Deneyde Kullanılan Dendroctonus micans (Kugelann) Erginlerinin Toplanması ve Ağaçlara Yerleştirilmesi}

Deneyde kullanılacak $D$. micans erginleri böceğin doğal olarak saldırmış olduğu ladin ağaçlarından toplanmıştır. D. micans erginleri tek tek tartılarak 29 mg'dan daha ağır olan erginler yani dişi oldukları belirlenenler (Robinson et al. 1984; Storer ve Speight 1996) deneyde kullanılmıştır. Doğu ladini ağaçlarının gövdelerinde, göğüs yüksekliğinde, artım burgusunun ucuyla ağacın kambiyum tabakasına kadar delik açılmıştır. Açılan deliğe bir $D$. micans dişisi yerleştirilmiş ve açılan deliğin üzerine şeffaf plastik bir kapak tutturulmuştur. Böylelikle ağaca yerleştirilen böceğin yere düşmemesi veya deliği terk ederek başka bir ağaca gitmemesi de güvence altına alınmıştır. Bu işlem her bir ağaçta dört ana yönde tekrar edilmiştir. D. micans dişileri ladin ağaçlarına 6 Temmuz 2015 tarihinde yerleştirilmiştir. 5 Kasım 2015 tarihinde de giriş delikleri açılarak değerlendirilmiştir.

\section{Deneme Alanlarında ve Ağaçlar Üzerinde Yapılan Ölçüm ve Sayımlar}

Deneme alanlarının yükseltisi, bakısı ve eğimi kaydedilmiştir. D. micans dişilerinin yerleştirildiği ağaçların çapı, boyu ve tepe boyu ölçülmüştür. Böceğin yerleştirildiği ağaçlara başarılı bir şekilde yerleşip yerleşemediği kaydedilmiştir. Her bir ağaçta, dört ana yönden birinden artım kalemi ve diğer yönlerden de son 10 yıllık büyümeyi / yıllık halkaları içeren artım kalemleri alınmıştır. Böceğin giriş deliklerinin bitişiğinden $48 \times 48$ $\mathrm{mm}$ büyüklüğünde floem örnekleri alınmıştır. Deneme alanlarındaki ağaçlar üzerinde yapılan ölçüm ve sayımlar Çizelge 1 ve Çizelge 2'de verilmiştir.

Çizelge 1 İlk deneme alanındaki ağaçlar üzerinde yapılan ölçüm ve sayımlar

\begin{tabular}{|c|c|c|c|c|c|}
\hline $\begin{array}{l}\text { Deneme Alanı } \\
\text { No }\end{array}$ & $\begin{array}{l}\text { Ağaç } \\
\text { No }\end{array}$ & $\begin{array}{l}\text { Çap } \\
\text { (cm) }\end{array}$ & $\begin{array}{l}\text { Boy } \\
\text { (m) }\end{array}$ & $\begin{array}{l}\text { Tepe boyu } \\
\text { (m) }\end{array}$ & Yaş \\
\hline 1 & 1 & 24 & 20 & 11 & 107 \\
\hline 1 & 2 & 26 & 22 & 14 & 96 \\
\hline 1 & 3 & 30 & 22 & 11 & 118 \\
\hline 1 & 4 & 33 & 22 & 17 & 182 \\
\hline 1 & 5 & 35 & 22 & 18 & 112 \\
\hline 1 & 6 & 34 & 21 & 13 & 126 \\
\hline 1 & 7 & 40 & 23 & 13 & 135 \\
\hline 1 & 8 & 38 & 25 & 12 & 88 \\
\hline 1 & 9 & 38 & 24 & 12 & 86 \\
\hline 1 & 10 & 50 & 25 & 16 & 106 \\
\hline 1 & 11 & 36 & 22 & 10 & 95 \\
\hline 1 & 12 & 35 & 22 & 11 & 100 \\
\hline 1 & 13 & 32 & 21 & 9 & 118 \\
\hline 1 & 14 & 36 & 22 & 12 & 100 \\
\hline 1 & 15 & 14 & 7 & 3 & 63 \\
\hline 1 & 16 & 40 & 19 & 12 & 78 \\
\hline 1 & 17 & 17 & 8 & 4 & 46 \\
\hline 1 & 18 & 26 & 20 & 11 & 71 \\
\hline 1 & 19 & 21 & 17 & 10 & 72 \\
\hline 1 & 20 & 20 & 15 & 6 & 60 \\
\hline 1 & 21 & 39 & 19 & 11 & 57 \\
\hline 1 & 22 & 19 & 14 & 7 & 47 \\
\hline 1 & 23 & 40 & 22 & 15 & 92 \\
\hline 1 & 24 & 48 & 20 & 8 & 132 \\
\hline 1 & 25 & 43 & 19 & 8 & 127 \\
\hline 1 & 26 & 32 & 17 & 7 & 167 \\
\hline 1 & 27 & 32 & 20 & 11 & 130 \\
\hline 1 & 28 & 34 & 20 & 12 & 132 \\
\hline 1 & 29 & 21 & 15 & 7 & 76 \\
\hline 1 & 30 & 28 & 16 & 7 & 61 \\
\hline 1 & 31 & 19 & 14 & 4 & 64 \\
\hline 1 & 32 & 23 & 17 & 5 & 67 \\
\hline 1 & 33 & 26 & 19 & 8 & 76 \\
\hline 1 & 34 & 31 & 23 & 12 & 89 \\
\hline 1 & 35 & 35 & 22 & 12 & 70 \\
\hline 1 & 36 & 29 & 24 & 10 & 76 \\
\hline 1 & 37 & 26 & 22 & 7 & 86 \\
\hline
\end{tabular}


Çizelge 2 íkinci deneme alanındaki ağaçlar üzerinde yapılan ölçüm ve sayımlar

\begin{tabular}{|c|c|c|c|c|c|}
\hline $\begin{array}{l}\text { Deneme Alanı } \\
\text { No }\end{array}$ & $\begin{array}{l}\text { Ağaç } \\
\text { No }\end{array}$ & $\begin{array}{l}\text { Çap } \\
\text { (cm) }\end{array}$ & $\begin{array}{l}\text { Boy } \\
\text { (m) }\end{array}$ & $\begin{array}{l}\text { Tepe boyu } \\
\text { (m) }\end{array}$ & Yaş \\
\hline 2 & 1 & 24 & 24 & 8 & 97 \\
\hline 2 & 2 & 28 & 15 & 6 & 81 \\
\hline 2 & 3 & 25 & 15 & 5 & 100 \\
\hline 2 & 4 & 26 & 15 & 5 & 70 \\
\hline 2 & 5 & 30 & 17 & 8 & 68 \\
\hline 2 & 6 & 28 & 15 & 7 & 84 \\
\hline 2 & 7 & 30 & 16 & 7 & 71 \\
\hline 2 & 8 & 28 & 14 & 6 & 117 \\
\hline 2 & 9 & 32 & 18 & 6 & 119 \\
\hline 2 & 10 & 33 & 17 & 6 & 130 \\
\hline 2 & 11 & 58 & 24 & 8 & 85 \\
\hline 2 & 12 & 38 & 22 & 7 & 74 \\
\hline 2 & 13 & 44 & 22 & 7 & 79 \\
\hline 2 & 14 & 38 & 20 & 6 & 75 \\
\hline 2 & 15 & 31 & 15 & 5 & 91 \\
\hline 2 & 16 & 29 & 18 & 6 & 117 \\
\hline 2 & 17 & 38 & 14 & 4 & 90 \\
\hline 2 & 18 & 37 & 19 & 8 & 88 \\
\hline 2 & 19 & 33 & 17 & 5 & 77 \\
\hline 2 & 20 & 32 & 19 & 6 & 99 \\
\hline 2 & 21 & 30 & 19 & 5 & 88 \\
\hline 2 & 22 & 41 & 19 & 5 & 88 \\
\hline 2 & 23 & 27 & 17 & 5 & 69 \\
\hline 2 & 24 & 54 & 27 & 10 & 85 \\
\hline 2 & 25 & 39 & 17 & 7 & 88 \\
\hline 2 & 26 & 35 & 20 & 6 & 110 \\
\hline 2 & 27 & 28 & 17 & 4 & 105 \\
\hline 2 & 28 & 47 & 23 & 9 & 116 \\
\hline 2 & 29 & 37 & 21 & 5 & 91 \\
\hline 2 & 30 & 54 & 26 & 10 & 112 \\
\hline 2 & 31 & 28 & 17 & 2 & 55 \\
\hline 2 & 32 & 29 & 18 & 6 & 65 \\
\hline 2 & 33 & 38 & 27 & 14 & 64 \\
\hline 2 & 34 & 32 & 19 & 7 & 67 \\
\hline 2 & 35 & 38 & 25 & 11 & 86 \\
\hline 2 & 36 & 36 & 25 & 12 & 73 \\
\hline
\end{tabular}

\section{Laboratuvarda Yapılan Ölçüm ve Sayımlar}

Ağaçların yaşının belirlenmesi için alınan artım kalemlerindeki yıllık halka sayısı, son yıla, son beş ve on yıla ait yıllık halka genişlikleri ve floem kalınlığı Leica M60 stereomikroskop ile sayılmış ve/veya ölçülmüştür. Ağaçlardan alınan $48 \times 48 \mathrm{~mm}$ büyüklüğündeki floem örnekleri, floemin nem içeriğinin yüzde oranının (\%) belirlenmesi için kullanılmıştır. Bunun için Storer ve Speight (1996)'da anlatılan yöntem izlenmiştir. Alının floem örnekleri araziden kapalı kutular içerisinde getirilip tartılmıştır. Arkasından 48 saat süreyle $80^{\circ} \mathrm{C}$ 'deki fırında kurutulmuş ve yeniden tartılmıştır. Nem oranı (\%), floem örneklerinin yaş ağırlıkları ve kuru ağırlıkları kullanılarak hesaplanmıştır (Storer ve Speight 1996). Birinci ve ikinci deneme alanından 30'ar ağaca ait kurutulmuş floem örneği daha sonra floemin organik madde içeriğinin belirlenmesi için kullanılmıştır. Küçük parçalara ayrılan floem örnekleri CHNS enstrümental analiz cihazında analize tabi tutularak içeriğindeki organik maddeler belirlenmiştir.

\section{CHNS Enstrümantal Analizi}

CHNS analizi için CHNS Elementer varioMAC80 CUBE elementer makro analiz cihazı kullanılmıştır. Analiz sırasında "plant" metodu kullanılmıştır. Örneklerin analizine başlamadan önce pure organik bir element olan sulfanilamid ile doğrulama yapılmıştır (C:41.81\%, $\mathrm{N}: 16.25 \%)$. Floem örnekleri toz haline getirilmiştir. Toz haline getirilen floem örneğinden $100 \mathrm{mg}$ alınarak kalay kapsül içine yerleştirilmiştir. Üzerine $\mathrm{WO}_{3}$ eklenerek preslenmiştir. Daha sonra örnekler sisteme yüklenerek ölçümleri yapılmıştır.

\section{İstatistik Analizler}

Arazideki ve laboratuardaki ölçüm ve sayımlar ile elde edilen veriler $T$ testi ile karşılaştırılmıştır. Veriler IBM SPSS 19.0 kullanılarak analiz edilmiştir.

\section{BULGULAR VE TARTIŞMA}

Deneme alanlarında toplam 73 ağaç üzerinde çalışılmıştır. Üst rakımda bulunan deneme alanının (1. deneme alanı) bakısı güneydoğu, eğimi \%25'tir. Alt rakımdaki deneme alanının (2. deneme alanı) bakısı güneybatı ve eğimi \%20'dir. Her bir ağaçtan alınan artım kalemlerinden yapılan sayım ve ölçüm değerleri, floem örneklerinden elde edilen ölçümler ve nem değerleri Çizelge 3 ve Çizelge 4 'te, 1 . ve 2 . deneme alanındaki 30'ar ağaçtan alınan floem örneğine ait enstrümantal analiz sonuçları ise Çizelge 5 'te verilmiştir.

D. micans dişileri, deneme alanlarında değerlendirilen 73 ağaçtan 50'sinde $(\% 68,5)$ başarılı olmuştur. Bu ağaçlardan 22 (\%44) tanesi 1975 m'deki 1. deneme alanında ve 28 (\%56) tanesi de $1680 \mathrm{~m}$ yükseltideki 2. deneme alanındadır (Çizelge 3, Çizelge 4). D. micans dişileri, 1. deneme alanındaki ağaçların $\% 59,5^{\prime}$ inde ve 2 . deneme alanındaki ağaçların \%77,8'inde başarılı olmuştur. íkinci deneme alanında böceğin başarılı olduğu ağaçların oranı her iki deneme alanı birlikte değerlendirildiğinde elde edilen ortalamadan yüksektir. 
Çizelge 3 Laboratuarda gerçekleştirilen ölçüm ve sayımlar (birinci deneme alanı)

\begin{tabular}{|c|c|c|c|c|c|c|c|c|}
\hline DA No & A No & Çap (cm) & SYA (mm) & S5YOA (mm) & S10YOA (mm) & FK $(\mathrm{mm})$ & BD & Nem (\%) \\
\hline 1 & 1 & 24 & 0,39 & 2,90 & 4,26 & 2,8 & 0 & 55,3 \\
\hline 1 & 2 & 26 & 0,76 & 4,43 & 3,17 & 4,9 & 1 & 53,8 \\
\hline 1 & 3 & 30 & 0,45 & 2,88 & 3,37 & 4,4 & 1 & 54,2 \\
\hline 1 & 4 & 33 & 0,58 & 3,21 & 3,89 & 5,4 & 1 & 49,4 \\
\hline 1 & 5 & 35 & 1,20 & 6,28 & 6,38 & 6,0 & 1 & 48,1 \\
\hline 1 & 6 & 34 & 0,63 & 4,34 & 6,50 & 6,1 & 1 & 46,1 \\
\hline 1 & 7 & 40 & 1,09 & 7,21 & 9,95 & 6,8 & 1 & 51,1 \\
\hline 1 & 8 & 38 & 0,68 & 4,79 & 5,03 & 6,6 & 0 & 51,6 \\
\hline 1 & 9 & 38 & 1,09 & 6,43 & 10,15 & 4,0 & 1 & 50,7 \\
\hline 1 & 10 & 50 & 1,43 & 7,27 & 7,69 & 5,1 & 0 & 54,4 \\
\hline 1 & 11 & 36 & 0,84 & 4,01 & 5,25 & 4,4 & 0 & 43,6 \\
\hline 1 & 12 & 35 & 1,0 & 7,24 & 7,24 & 4,2 & 1 & 49,5 \\
\hline 1 & 13 & 32 & 0,89 & 4,23 & 5,46 & 2,6 & 1 & 47,5 \\
\hline 1 & 14 & 36 & 1,91 & 8,05 & 9,75 & 3,5 & 0 & 54,9 \\
\hline 1 & 15 & 14 & 0,48 & 2,32 & 2,76 & 1,8 & 1 & 47,6 \\
\hline 1 & 16 & 40 & 1,26 & 6,59 & 8,90 & 5,5 & 1 & 50,8 \\
\hline 1 & 17 & 17 & 0,95 & 4,98 & 6,25 & 4,5 & 1 & 49,5 \\
\hline 1 & 18 & 26 & 0,83 & 3,65 & 3,18 & 3,3 & 1 & 51,1 \\
\hline 1 & 19 & 21 & 0,85 & 4,88 & 6,10 & 2,1 & 1 & 47,8 \\
\hline 1 & 20 & 20 & 1,20 & 4,58 & 3,88 & 1,3 & 1 & 49,4 \\
\hline 1 & 21 & 39 & 2,10 & 9,78 & 12,30 & 2,9 & 1 & 50,0 \\
\hline 1 & 22 & 19 & 0,72 & 3,39 & 3,61 & 3,2 & 1 & 51,5 \\
\hline 1 & 23 & 40 & 1,03 & 5,10 & 6,00 & 3,5 & 1 & 52,5 \\
\hline 1 & 24 & 48 & 1,47 & 9,16 & 11,44 & 3,7 & 0 & 47,3 \\
\hline 1 & 25 & 43 & 0,95 & 5,90 & 8,55 & 3,7 & 1 & 52,9 \\
\hline 1 & 26 & 32 & 0,75 & 3,16 & 3,58 & 2,4 & 0 & 57,4 \\
\hline 1 & 27 & 32 & 1,45 & 8,05 & 5,48 & 4,0 & 1 & 38,8 \\
\hline 1 & 28 & 34 & 1,38 & 6,4 & 5,03 & 3,4 & 0 & 86,2 \\
\hline 1 & 29 & 21 & 0,20 & 1,14 & 1,91 & 2,6 & 0 & 48,5 \\
\hline 1 & 30 & 28 & 2,3 & 9,45 & 10,15 & 4,2 & 0 & 48,1 \\
\hline 1 & 31 & 19 & 1,20 & 7,73 & 7,05 & 3,6 & 0 & 42,9 \\
\hline 1 & 32 & 23 & 0,81 & 4,98 & 6,05 & 1,8 & 0 & 53,6 \\
\hline 1 & 33 & 26 & 0,65 & 4,55 & 4,50 & 2,7 & 0 & 47,9 \\
\hline 1 & 34 & 31 & 0,58 & 4,68 & 5,70 & 1,7 & 0 & 47,5 \\
\hline 1 & 35 & 35 & 0,75 & 7,00 & 7,63 & 4,9 & 1 & 44,6 \\
\hline 1 & 36 & 29 & 0,53 & 3,13 & 4,93 & 3,4 & 0 & 47,1 \\
\hline 1 & 37 & 26 & 0,50 & 4,23 & 5,28 & 3,1 & 1 & 52,1 \\
\hline
\end{tabular}

SYA: Son yıldaki ortalama artım, S5YOA: Son 5 yıllık ortama artım, S10YOA: Son 10 yıllık ortama artım, FK: Floem kalınlığı, BD: D. micans'ın başarı durumu (0: başarısız, 1: başarılı)

Birinci deneme alanında ağaç boyu, yaşı, son yıldaki ortalama artım, floem kalınlığı, karbon miktarı 2. deneme alanından daha fazladır. Fakat bu fark anlamlı değildir ( $p>$ 0,05). İinci deneme alanında ağaçların çapı, floem örneklerindeki nem miktarı 1. deneme alanından daha yüksektir. Ancak, bu değereler bakımından deneme alanları arasındaki fark anlamlı değildir $(p>0,05)$.

Son 5 yıllık ve 10 yıllık ortalama artım 2. deneme alanında daha düşüktür. Bu fark son 10 yıllık ortalama artım için istatiksel olarak anlamlıdır (t: 2,275, df: 71, $\mathrm{p}<0,05$ ). Alkan-Akıncı ve Erşen-Bak (2016) D. micans'ın, son yıllarda büyümesi yavaşlamış olan güçlü ağaçlara saldırdığını ve ladin ormanlarında stres altıda kalan veya zarar gören güçlü ağaçların meşcerelerde epidemi oluşturabilecek populasyonlara neden olabileceğini belirtmiştir. 
Çizelge 4 Laboratuarda gerçekleştirilen ölçüm ve sayımlar (ikinci deneme alanı)

\begin{tabular}{|c|c|c|c|c|c|c|c|c|}
\hline DA No & A No & Çap $(\mathrm{cm})$ & SYA (mm) & S5YOA (mm) & S10YOA (mm) & FK (mm) & BD & Nem (\%) \\
\hline 2 & 1 & 24 & 0,70 & 3,02 & 2,57 & 3,4 & 1 & 51,4 \\
\hline 2 & 2 & 28 & 1,23 & 6,35 & 5,4 & 2,1 & 1 & 56,3 \\
\hline 2 & 3 & 25 & 0,82 & 3,95 & 3,25 & 4,1 & 1 & 53,2 \\
\hline 2 & 4 & 26 & 1,36 & 6,45 & 5,66 & 2,3 & 1 & 51,5 \\
\hline 2 & 5 & 30 & 1,33 & 7,63 & 6,37 & 3,2 & 1 & 53,3 \\
\hline 2 & 6 & 28 & 0,82 & 3,85 & 3,88 & 3,2 & 1 & 46,2 \\
\hline 2 & 7 & 30 & 0,70 & 3,28 & 3,5 & 1,7 & 1 & 52,9 \\
\hline 2 & 8 & 28 & 0,13 & 0,85 & 1,36 & 3,9 & 1 & 53,7 \\
\hline 2 & 9 & 32 & 0,78 & 4,15 & 3,95 & 1,6 & 1 & 52,3 \\
\hline 2 & 10 & 33 & 0,55 & 2,55 & 1,60 & 4,6 & 0 & 58,5 \\
\hline 2 & 11 & 58 & 2,37 & 8,60 & 8,35 & 3,4 & 1 & 54,7 \\
\hline 2 & 12 & 38 & 0,95 & 4,78 & 4,35 & 2,8 & 1 & 56,5 \\
\hline 2 & 13 & 44 & 1,63 & 7,15 & 6,85 & 3,3 & 0 & 50,0 \\
\hline 2 & 14 & 38 & 1,18 & 6,40 & 7,43 & 2,3 & 0 & 54,5 \\
\hline 2 & 15 & 31 & 0,67 & 3,64 & 3,91 & 1,1 & 1 & 55,0 \\
\hline 2 & 16 & 29 & 0,30 & 1,40 & 2,40 & 3,2 & 1 & 50,0 \\
\hline 2 & 17 & 38 & 1,03 & 4,97 & 5,07 & 4,2 & 1 & 82,7 \\
\hline 2 & 18 & 37 & 0,43 & 2,70 & 3,75 & 4,8 & 1 & 54,5 \\
\hline 2 & 19 & 33 & 0,60 & 3,83 & 4,43 & 1,98 & 1 & 50,8 \\
\hline 2 & 20 & 32 & 0,68 & 3,33 & 3,43 & 2,4 & 1 & 52,5 \\
\hline 2 & 21 & 30 & 0,68 & 3,75 & 3,68 & 2,9 & 1 & 56,6 \\
\hline 2 & 22 & 41 & 0,48 & 2,80 & 3,83 & 4,2 & 0 & 56,5 \\
\hline 2 & 23 & 27 & 0,35 & 1,88 & 2,60 & 1,9 & 1 & 51,8 \\
\hline 2 & 24 & 54 & 0,83 & 4,40 & 5,55 & 4,0 & 0 & 47,7 \\
\hline 2 & 25 & 39 & 1,03 & 5,40 & 5,48 & 2,1 & 0 & 56,7 \\
\hline 2 & 26 & 35 & 0,47 & 2,55 & 3,08 & 2,6 & 1 & 57,8 \\
\hline 2 & 27 & 28 & 0,68 & 2,68 & 3,00 & 2,1 & 1 & 54,5 \\
\hline 2 & 28 & 47 & 1,30 & 7,33 & 7,65 & 2,8 & 1 & 52,3 \\
\hline 2 & 29 & 37 & 0,48 & 2,95 & 3,18 & 4,0 & 1 & 56,5 \\
\hline 2 & 30 & 54 & 1,55 & 9,55 & 7,55 & 3,8 & 1 & 49,1 \\
\hline 2 & 31 & 28 & 1,25 & 6,48 & 7,17 & 2,5 & 1 & 48,0 \\
\hline 2 & 32 & 29 & 1,35 & 6,70 & 9,63 & 4,0 & 0 & 53,3 \\
\hline 2 & 33 & 38 & 1,40 & 7,55 & 7,65 & 4,8 & 0 & 50,0 \\
\hline 2 & 34 & 32 & 0,80 & 4,40 & 4,75 & 1,9 & 1 & 53,2 \\
\hline 2 & 35 & 38 & 0,75 & 4,23 & 4,78 & 2,2 & 1 & 47,2 \\
\hline 2 & 36 & 36 & 1,55 & 7,93 & 9,63 & 3,2 & 1 & 46,8 \\
\hline
\end{tabular}

SYA: Son yıldaki ortalama artım, S5YOA: Son 5 yıllık ortama artım, S10YOA: Son 10 yıllık ortama artım, FK: Floem kalınlığı, BD: D. micans'ın başarı durumu (0: başarısız, 1: başarılı)

Birinci ve ikinci deneme alanlarındaki ağaçlardan alınan floem örneklerindeki azot miktarı 2. deneme alanındaki ağaçlarda daha fazladır. Belirlenen bu fark istatiksel olarak da anlamlıdır (t: 2,057, df: 71, $\mathrm{p}<0,05$ ). Karbonhidrat ve azot gibi önemli böcek besin maddelerinin (Scriber ve Slansky 1981; Kirkendal 1983; Storer ve Speight 1996; Reid ve Robb 1999) güçlü bir şekilde büyüyen ağaçlarda daha yüksek olduğu belirtilmektedir (Sundberg et al. 1993; Reid ve Robb 1999). İkinci deneme alanındaki ağaçların tepe boyu 1. deneme alanındaki ağaçlardan daha kısadır. Bu fark istatiksel olarak anlamlıdır (t: 4,744, df: 71, $p<0,05$ ). Jakuš et al. (2011) tepe boyu uzun olan ladin ağaçlarının, önemli bir kabukböceği türü olan ve Avrupa'da ve ülkemizde milyonlarca ladin ağacını kurutan Ips typographus (L.) (Coleoptera: Curculionidae) saldırılarını ölmeden atlatabildiklerini kaydetmiştir. İkinci deneme alanındaki ağaçlar son 10 yıl içinde giderek azalan bir hızda büyümektedir. İkinci deneme alanındaki ağaçlarda floem kalınlığı ilk deneme alanına göre daha ince olmasına rağmen floemin nem içeriği ikinci deneme alanında daha fazladır. D. micans'ın floemin nem içeriğinin yüksek olduğu ve böcek besin maddelerinin fazla olduğu yerlere yumurta koyduğu kaydedilmiştir. Böylece, yumurtaların bırakıldığı gelişme ortamının, yumurtadan çıkan larvaların başarılı bir şekilde gelişimine olanak sağladığı sonucu vurgulanmaktadır (Storer ve Speight 1996). Her iki deneme alanındaki ağaçların boyları birbirine yakındır. Illk ve ikinci deneme alanındaki ağaç boyları sırasıyla ortalama $19,51 \mathrm{~m}$ ve $19,25 \mathrm{~m}$ 'dir. Ancak ağaçların tepe boyu arasındaki fark anlamlıdır. İkinci deneme alanındaki ağaçlar daha kısa tepe boyuna sahiptir. 
Çizelge 5 Deneme alanlarından alınan floem örneklerine ait enstrümantal analiz sonuçları

\begin{tabular}{|c|c|c|c|c|c|c|c|}
\hline DA No & Ağaç No & $\% \mathrm{C}$ & $\% \mathbf{N}$ & DA No & Ağaç No & $\% \mathrm{C}$ & $\% N$ \\
\hline 1 & 1 & 45,20 & 0,62 & 2 & 1 & 45,79 & 0,49 \\
\hline 1 & 2 & 47,04 & 0,56 & 2 & 2 & 47,53 & 0,47 \\
\hline 1 & 3 & 46,63 & 0,64 & 2 & 3 & 47,25 & 0,43 \\
\hline 1 & 4 & 46,34 & 0,57 & 2 & 4 & 46,36 & 0,54 \\
\hline 1 & 5 & 46,38 & 0,63 & 2 & 5 & 48,53 & 0,50 \\
\hline 1 & 6 & 46,98 & 0,60 & 2 & 6 & 45,35 & 0,47 \\
\hline 1 & 7 & 46,72 & 0,70 & 2 & 7 & 45,87 & 0,45 \\
\hline 1 & 8 & 46,50 & 0,45 & 2 & 8 & 47,52 & 0,50 \\
\hline 1 & 9 & 45,91 & 0,50 & 2 & 9 & 46,08 & 0,50 \\
\hline 1 & 10 & 46,46 & 0,53 & 2 & 11 & 47,37 & 0,61 \\
\hline 1 & 11 & 48,83 & 0,67 & 2 & 12 & 48,68 & 0,54 \\
\hline 1 & 12 & 46,22 & 0,57 & 2 & 15 & 46,38 & 0,53 \\
\hline 1 & 13 & 45,95 & 0,50 & 2 & 16 & 45,31 & 0,65 \\
\hline 1 & 14 & 46,76 & 0,53 & 2 & 17 & 45,01 & 0,51 \\
\hline 1 & 15 & 45,30 & 0,46 & 2 & 18 & 47,58 & 0,53 \\
\hline 1 & 16 & 47,02 & 0,54 & 2 & 19 & 45,49 & 0,51 \\
\hline 1 & 17 & 45,17 & 0,38 & 2 & 20 & 47,20 & 0,67 \\
\hline 1 & 18 & 46,73 & 0,36 & 2 & 21 & 45,21 & 0,48 \\
\hline 1 & 19 & 46,19 & 0,41 & 2 & 23 & 46,76 & 0,54 \\
\hline 1 & 20 & 44,47 & 0,49 & 2 & 24 & 47,32 & 0,74 \\
\hline 1 & 21 & 47,33 & 0,42 & 2 & 25 & 48,17 & 0,61 \\
\hline 1 & 22 & 44,91 & 0,47 & 2 & 26 & 48,52 & 0,58 \\
\hline 1 & 23 & 46,94 & 0,53 & 2 & 27 & 47,64 & 0,66 \\
\hline 1 & 24 & 46,96 & 0,43 & 2 & 28 & 48,02 & 0,52 \\
\hline 1 & 25 & 47,48 & 0,45 & 2 & 29 & 46,89 & 0,52 \\
\hline 1 & 26 & 48,66 & 0,47 & 2 & 30 & 45,55 & 0,69 \\
\hline 1 & 27 & 51,71 & 0,33 & 2 & 31 & 47,01 & 0,42 \\
\hline 1 & 28 & 52,30 & 0,44 & 2 & 34 & 46,52 & 0,62 \\
\hline 1 & 35 & 45,28 & 0,40 & 2 & 35 & 46,52 & 0,86 \\
\hline 1 & 37 & 51,70 & 0,45 & 2 & 36 & 46,24 & 0,49 \\
\hline
\end{tabular}

\section{SONUÇ VE ÖNERILER}

Sonuç olarak, D. micans'ın son 10 yıldır artımın azaldığı, tepe boyunun kısa olduğu ve floemin azot içeriğinin fazla olduğu ladin ağaçlarında başarılı bir şekilde geliştiği tespit edilmiştir.

Bu çalışmanın sonuçları D. micans'ın konukçu seçimi ile ilgili temel bilgilerin ortaya koyulmasına katkı sağlamıştır. Ladin meşcerelerinde deneysel olarak elde edilen verilerin $D$. micans'ın doğal şartlarda istila ettiği ağaçlar üzerinde ve daha geniş bir alanda araştırılması konunun daha geniş ölçekte ortaya koyulmasına katkı sağlayacaktır.

\section{TEŞEKKÜR}

Bu çalışma, 2015.F10.02.08 nolu proje kapsamında Artvin Çoruh Üniversitesi, Bilimsel Araştırma Projeleri Koordinatörlüğü tarafından desteklenmiştir.

\section{KAYNAKLAR}

Acatay A (1968) Türkiye'de Yeni Bir Ladin Tahripçisi, Dendroctonus micans Kug. iÜ Orman Fakültesi Dergisi 18 (1): 18-36

Aksu Y (2011) Rhizophagus grandis Gyll. (Coleoptera: Rhizophagidae)'in biyolojisi, laboratuarda üretim yöntemleri, ormanlara salınması ve mücadele sonuçları. In: Proceedings of Türkiye I. Orman Entomolojisi ve Patolojisi Sempozyumu. 23-25 Kasım 2011, Antalya, pp 73-79

Alkan Ş (1985) Şavşat İ̧̧letmesi Ormanlarında Dendroctonus micans Kug. (Dev soymuk böceği). Orman Mühendisliği Dergisi 1: 59-62

Alkan Ş, Aksu Y (1990) Rhizophagus grandis Gyll. (Coleoptera, Rhizophagidae)'in Üretilmesinde Yeni Bir Metodun Uygulanması Üzerine Araştırmalar. In: Proceedings of Türkiye II. Biyolojik Mücadele Kongresi. 26-29 Eylül, Ankara, pp 173-179

Alkan-Akıncı H, Erşen-Bak F (2016) Assessment of Tree Vigor Parameters in Successful Establishment of Dendroctonus micans on Picea orientalis in Turkey. J Entomol Res Soc 18 (1): 119-125

Alkan-Akıncı H, Eroğlu M, Özcan GE (2014) Attack strategy and development of Dendroctonus micans (Kug.) (Coleoptera: Curculionidae) on oriental spruce in Turkey. Turkish Journal of Entomology 38 (1): 31-41

Alkan-Akıncı H, Özcan GE, Eroğlu M (2009) Impacts of site effects on losses of oriental spruce during Dendroctonus micans (Kug.) outbreaks in Turkey. African Journal of Biotechnology 8 (16): 3934-3939 
Besçeli Ö, Varol M, Ekici M (1968) Posof Ormanlarında Tahribat Yapan Dendroctonus micans Kug. Üzerinde Bir Etüt. Ormancılık Araştırma Enstitüsü Dergisi 14 (2): 26-40

Carle P (1975) Dendroctonus micans Kug. (Col: Scolytidae), l'hylésine géant où dendroctone de l'épicéa (note bibliographique). Revue Forestière Française 27: 115-128

Carle P, Granet AM, Perrot JP (1979) Contribution à l'étude de la dispersion et de l'agressivité chez Dendroctonus micans Kug en France. Mitteilungen der Schweizerischen Entomologischen Gesellschaft 52: 185-196

Eroğlu M (1995) Dendroctonus micans (Kug.) (Coleoptra, Scolytidae)'ın Populasyon Dinamiğine Etki Eden Faktörler Üzerine Araştırmalar. In: Proceedings of I. Ulusal Karadeniz Ormancllık Kongresi. 23-25 Ekim 1995, Trabzon, 3. Cilt, pp 148-159

Fielding NJ, Evans HF, Williams JM, Evans B (1991) Distribution and spread of the Great European Spruce Bark Beetle, Dendroctonus micans, in Britain-1982 to 1989. Forestry 64 (4): 345-358

Fielding NJ, Evans HF (1997) Biological control of Dendroctonus micans (Scolytidae) in Great Britain. Biocontrol News and Information 18 (2): 51-60

Gilbert M, Fielding N, Evans HF, Grégoire JC (2003) Spatial pattern of invading Dendroctonus micans (Coleoptera: Scolytidae) populations in the United Kingdom. Can J For Res 33: 712-725

Gilbert M, Vouland G, Grégoire JC (2001) Past attacks influence host selection by the solitary bark beetle Dendroctonus micans. Ecological Entomology 26: 133-142

Göktürk T, Kordalı Ş, Çalmaşur Ö, Tozlu G (2011) Insecticidal effects of essential plant oils against larvae of great spruce bark beetle, Dendroctonus micans (Kugelann) (Coleoptera: Curculionidae: Scolytinae). Fresenius Environmental Bulletin 20 (9a): 2365-2370

Grégoire JC (1985) Dendroctonus micans in Belgium: The situation today. In: Proceedings of the EEC Seminar Biological Control of Bark Beetles (Dendroctonus micans). 3-4 October 1984, Brussels, Belgium, pp 48-62

Grégoire JC (1988) Greater European Spruce Beetle, Dendroctonus micans. In Berryman AA (ed) Dynamics of forest insect populations: patterns, causes, implications, Plenum Pres, New York, pp 455-478

Jakuš R, Edwards-Jonášová $M$, Cudlín $P$, Blaženek $M$, Ježík M, Havlíček F, Moravec I (2011) Characteristics of Norway spruce trees (Picea abies) surviving a spruce bark beetle (Ips typographus L.) outbreak. Trees DOI 10.1007/s00468-011-0571-9

Kirkendall LR (1983) The evolution of mating systems in bark and ambrosia beetles (Coleoptera: Scolytidae and Platypodidae). Zoological Journal of the Linnean Society 77: 293-352

Khobakhidze D (1967) Dev Soymuk Böceği (Dendroctonus micans Kugelann) Gürcistan'da. Çeviren Prof. Dr. Gafur Acatay. Ormancilık Araştırma Enstitüsü Dergisi 14 (2): 3-10

Lieutier $F(2007)$ Host resistance to bark beetles and its variations. Lieutier F, Day KR, Battisti A, Grégoire JC, Evans HF (ed) Bark and Wood Boring Insects in Living Trees in Europe, a Synthesis, Springer, Dordrecht, pp 135-180

Reid ML, Robb T (1999) Death of vigorous trees benefits bark beetles. Oecologia 120: 555-562

Robinson MN, Grégoire JC, De Vos L (1984) A method of sexing live Dendroctonus micans. In: Proceedings of the EEC Seminar Biological Control of Bark Beetles (Dendroctonus micans). 3-4 October 1984, Brussels, Belgium, pp 63-67

Scriber JM, Slansky $F$ (1981) The nutritional ecology of immature insects. Annual Review of Entomology 26: 183-211

Selmi E (1998) Türkiye Kabuk Böcekleri ve Savaşı. İstanbul Üniversitesi Yayın No: 4042, Emek Matbaacilık, İstanbul

Serez M (1979) Türkiye'de Dendroctonus micans (Kugelann) Üzerinde Araştırmalar. KTÜ Orman Fakültesi Dergisi 2 (1): 106-134

Severin G (1902) L'invasion de l'hylésine géante. Bulletin de la Société Centrale Forestié re de Belgique 9: 145-152

Storer AJ, Speight MR (1996) Relationships between Dendroctonus micans (Kug.) (Coleoptera: Scolytidae) survival and development and biochemical changes in Norway spruce, Picea abies (L.) Karst., phloem caused by mechanical wounding. Journal of Chemical Ecology 22: 559-573

Storer AJ, Wainhouse D, Speight MR (1997) The effect of larval aggregation behaviour on larval growth of the spruce bark beetle Dendroctonus micans. Ecological Entomology 22: 109-115

Sundberg B, Ericsson A, Little CHA, Nasholm TOA, Gref R (1993) The relationship between crown size and ring width in Pinus sylvestris L. stems: dependence on indole-3-acetic acid, carbohydrates and nitrogen in the cambial region. Tree Physiology 12: 347-362. 